\title{
International Epidemiology of Anterior Cruciate Ligament Injuries
}

\author{
Neeraj Singh* \\ Department of Neurology, USA \\ *Corresponding author: Neeraj Singh, Department of Neurology, USA \\ Submission: 海 December 20, 2017; Published: 眥 February 08, 2018
}

\begin{abstract}
Anterior cruciate ligament, or ACL, injuries are among the most common athletic injuries that occur in the world. While many studies focus on understanding which sports pose the greatest risk for ACL injuries and the differences in injury rates between female and male athletes, there have been fewer studies compare ACL injury rates among different countries. This paper reviews the studies that have examined ACL injury rates in different countries, to help understand whether there may be genetic or geographic contributions to differences in these rates. This information can guide the design for future prospective studies on international ACL injuries.
\end{abstract}

Keywords: Anterior cruciate ligament; Athletes; Injuries

Abbreviations: ACL: Anterior Cruciate Ligament; NCAA: National Collegiate Athletic Association

\section{Mini-Review}

The anterior cruciate ligament (ACL), the knee ligament that runs from the posterior medial aspect of the lateral femoral condyle in the intercondylar notch to the anterior aspect of the intercondylar eminence of the tibia, limits anterior movement of the tibia relative to the femur. As such, it is the knee ligament most often ruptured by athletes. While the ACL can be ruptured due to contact injuries, it is more often ruptured due to non-contact injuries, usually when an athlete hyperextends the knees or suddenly changes direction while moving.

Current studies on ACL injuries have focused on trying to explain which sports place an athlete at greatest risk for ACL injuries, or why female athletes are more likely to suffer from ACL injuries than male athletes in a given sport. However, very little research has been conducted on how the incidences, or numbers of new cases per year, of ACL injuries compare among different countries. In this review, we look at studies on ACL injuries in the general populations of select countries, and in populations of athletes of specific sports in different countries, to see how their injury incidences compare.

It is estimated that in the United States of America (USA), there are 200,000 ACL injuries, half of which require reconstructive surgeries. However, currently only Norway, Denmark, and Sweden have national web-based registries that accurately record nationwide ACL reconstructions, which are presumed to reflect the incidences of ACL injuries [1]. Norway's registry was established in 2004 [2], while the registries in Denmark and Sweden were established in 2005 [1]. Denmark is the only country to mandate reporting of ACL injuries to its registry [3]. Based on reviews of these registries since their first entries, the incidences of ACL injuries were 34 per 100,000 people in Norway, 38 per 100,000 people in Denmark, and 32 per 100,000 people in Sweden.

Other studies using insurance claims for ACL reconstructions have found incidences of 32 per 100,000 people in Germany based on data from the 1990s [1], 37 per 100,000 people in New Zealand based on data from 1 July 2000 to 30 June 2005 [4], and 29 per 100,000 people in the USA based on data from 1997 to 2006 [5]. However, data from these countries spanning only 2004 to 2006 show ACL incidences between 30 and 36 per 100,000 people, which is a similar range of incidences to those seen in the Scandinavian registries during the same period of time [5]. Overall, the data from these countries and the Scandinavian ones appear to show only a small variation in ACL injury incidences of entire national populations.

Although national incidences of ACL injuries from these six countries appear to fall within a range of 29 to 38 per 100,000 people, studies of athletes playing the same sport in different countries have shown very different injury incidences. This is seen even as incidences are reported using different denominators; some studies report incidences as injuries per athlete per day, while others report them as injuries per athletic exposure. An athletic exposure is defined as one athlete participating in a single game or practice session that could expose him or her to injury [6]. Although many studies were prospective and therefore were able to 
calculate ACL injury incidences, others were retrospective analyses that could not include incidence calculations in their design. These retrospective studies instead reported ACL injury prevalences, or total cases over the time period of the study, and present them as percentages of total injuries.

One study in the USA analyzed National Collegiate Athletic Association (NCAA) soccer players and found an ACL injury incidence of 14 per 100,000 athletic exposures per year between 1989 and 2004 [6]. Another study of Italian semi-professional and amateur soccer players found an ACL injury incidence of 7.7 per 100,000 players per day between 1993 and 1996 [7]. Meanwhile, a retrospective study of French soccer players who competed at the district, regional, and national levels between 1991 and 2003 found an ACL injury prevalence of $1.58 \%$ [8].

Differences are also seen in the sport of skiing. A study on skiers in the USA found an ACL injury incidence of 50 per 100,000 skiers per day in the USA between 1991 and 1994 [9]. Lower incidences have been found in studies from other countries. A study of elite French alpine skiers between 1980 and 2005 found an ACL injury incidence of 5.7 per 100 skiers per season, which is equivalent to 47 per 100,000 skiers per day [10]. Another study of skiers in Turkey during the 2003-2004 season found a knee injury rate 1.14 per 1,000 skiers per day, which is equivalent to 114 per 100,000 skiers per day [11]. However, only $27.1 \%$ of these were ACL injuries, so the actual ACL injury incidence was 30.9 per 100,000 skiers per day [11].

In the sport of basketball, the study of NCAA players in the USA found an ACL injury incidence of 17 per 100,000 athletic exposures between 1989 and 2004 [6]. Studies from other countries revealed ACL injury prevalence data: a prevalence of 7.0\% among basketball players in Australia between 2000 and 2004 [12], and a prevalence of $10.6 \%$ among high school basketball players in Calgary, Canada in 2004 [13].

Although rates of ACL injuries have been expressed differently in the various studies, the results show that while there may be little variation in nationwide differences in ACL injury incidence, there appear to be more distinct differences in ACL injury incidence and prevalence in athletes playing the same sport in different countries. This suggests that the differences seen are not due to genetic or environmental differences among populations of different countries, but rather due to differences in athletic training in these countries. Attention should therefore be focused on how to improve athletic sports programs to prevent ACL injuries among athletes.

One method to prevent non-contact ACL injuries, known as proprioceptive training, has been promoted in Italy. A study of Italian soccer players found that a regimen of increasingly difficult balancing exercises for twenty minutes every day allowed players to have a lower ACL injury incidence than those who did not undergo this proprioceptive training [14]. Indeed, in the comparison of ACL injury incidences in soccer players, the Italian athletes appear to have a low ACL injury incidence [7]. Meanwhile, other research has shown that one such training strategy, restraining internal tibial rotation, makes it more difficult for the ACL to be injured because it reduces the compressive impact load on the knee [15].

Meanwhile, to prevent contact ACL injuries, a study from Japan suggests a simpler approach. This study of Japanese judo players found that certain stances left players exposed to kicks that could result in contact ACL ruptures [16]. This study suggests that education about risky stances and movements can be useful in reducing contact ACL injuries among judo players [15]. Such education programs about risky positions have also been proposed in the study on Italian skiers to prevent contact ACL injuries in that sport [6].

Recent studies have identified neuromuscular dysfunction as the characteristic that informs an athlete's status before, during, and after an ACL injury [17]. For example, the range of motion of knee abduction was found to have a significant predictive value for post-ACL injury status [17]. As a result, specific neuromuscular retraining intervention programs have been developed, including the HarmoKnee program in Sweden for soccer players and the Sports metrics program in the United States for such sports as basketball and volleyball [18].

Although it is not possible to make statistical comparisons among the studies of ACL injury rates in national populations or in groups of athletes, the results from these studies suggest that these differences may not be significant among entire populations, but may be significant among athletes playing the same sport in different countries. More research must be done on ACL injury incidences in entire populations and in athletes from countries that are currently underrepresented in the literature on this topic, namely countries in Africa, Asia, and South America. The establishment of national injury registries outside of Scandinavia, even if they depend on voluntary reporting, would facilitate such research and provide a more global picture on national ACL injury incidences.

To determine whether ACL injury incidences differ among athletes of the same sport under different training regimens, a prospective study could be designed to make two comparisons: (1) ACL injury incidences among entire populations from different countries, using either injury registries or insurance claim data, to definitively rule out factors unique to each country, and (2) ACL injury incidences among athletes playing the same sport in each country, with some undergoing proprioceptive training or injury prevention education and others not undergoing such training or education. Such a study would clarify any differences among countries, as well as any differences between those with special athletic preparation and those without. The results of such a study would provide us with a clearer picture of how people, especially athletes, around the world can forestall ACL injuries and the need for reconstructive surgery.

\section{References}

1. Granan LP, Forssblad M, Lind M, Engebretsen L (2009) The Scandinavian ACL registries 2004-2007: baseline epidemiology. Acta Orthop 80(5): 563-567.

2. Granan LP, Bahr R, Steindal K, Furnes O, Engebretsen L (2008) Devel- 
opment of a national cruciate ligament surgery registry: the Norwegian National Knee Ligament Registry. Am J Sports Med 36(2): 308-315.

3. Lind M, Menhert F, Pedersen AB (2009) The first results from the Danish ACL reconstruction registry: epidemiologic and 2 year follow-up results from 5,818 knee ligament reconstructions. Knee Surg Spors Traumatol Arthrosc 17(2): 117-124.

4. Gianotti SM, Marshall SW, Hume PA, Bunt L (2009) Incidence of anterior cruciate ligament injury and other knee ligament injuries: A national population-based study. J Sci Med Sport 12(6): 622-627.

5. Lyman S, Koulouvaris P, Sherman S, Do H, Mandl LA, et al. (2009) Epidemiology of anterior cruciate ligament reconstruction: trends, readmissions, and subsequent knee surgery. J Bone Joint Surg Am 91(10): 2321-2328

6. Mihata LC, Beutler AI, Boden BP (2006) Comparing the incidence of anterior cruciate ligament injury in collegiate lacrosse, soccer, and basketball players: implications for anterior cruciate ligament mechanism and prevention. Am J Sports Medi 4(6): 899-904.

7. Caraffa A, Cerulli G, Projetti M, Aisa G, Rizzo A (1996) Prevention of anterior cruciate ligament injuries in soccer. A prospective controlled study of proprioceptive training. Knee Surg Sports Traumatol Arthrosc 4(1): $19-21$.

8. Rochcongar P, Laboute E, Jan J, Carling C (2009) Ruptures of the anterior cruciate ligament in soccer. Int J Sports Med 30(5): 372-378.

9. Ettlinger CF, Johnson RJ, Shealy JE (1995) A method to help reduce the risk of serious knee sprains incurred in alpine skiing. Am J Sports Med 23(5): 531-537.

10. Pujol N, Blanchi MP, Chambat P (2007) The incidence of anterior cruci- ate ligament injuries among competitive Alpine skiers: a 25-year investigation. Am J Sports Med 35(7): 1070-1074.

11. Demirag B, Oncan T, Durak K (2004) An evaluation of knee ligament injuries encountered in skiers at the Uludag Ski Center. Acta Orthop Traumatol Turc 38(5): 313-316.

12. Flood L, Harrison JE (2009) Epidemiology of basketball and netball injuries that resulted in hospital admission in Australiia, 2000-2004. Med J Aust 190(2): 87-90.

13. Emery CA, Meeuwisse WH, McCallister JR (2006) Survey of sport participation and sport injury in Calgary and area high schools. Clin J Sports Med 16(1): 20-26

14. Cerulli G, Benoit DL, Caraffa A, Ponteggia F. (2001) Proprioceptive training and prevention of anterior cruciate ligament injuries in soccer. J Orthop Sports Phys Ther 31(11): 655-660.

15. Mokhtarzadeh H, Ng A, Yeow CH, Oetomo D, Malekiopur F, et al. (2015) Restrained tibial rotation may prevent ACL injury during landing at different flexion angles. Knee 22(1): 24-29.

16. Koshida S, Deguchi T, Miyashita K, Iwai K, Urabe Y (2010) The common mechanism of anterior cruciate ligament injuries in judo: A retrospective analysis. Br J Sports Med 44(12): 856-861.

17. Di Stasi S, Myer GD, Hewett TE (2013) Neuromuscular training to target deficits associated with second anterior cruciate ligament injury. J Orthop Sports Phys Ther 43(11): 777-792.

18. Noyes FR, Barber-Westin SD (2014) Neuromuscular retraining intervention programs: do they reduce noncontact anterior cruciate ligament injury rates in adolescent female athletes? Arthroscopy 30(2): 245-255.
Creative Commons Attribution 4.0

International License
For possible submission use the below is the URL
Submit Article

\section{Your subsequent submission with Crimson Publishers will attain the below benefits}

- High-level peer review and editorial services

- Freely accessible online immediately upon publication

- Authors retain the copyright to their work

- Licensing it under a Creative Commons license

- Visibility through different online platforms

- Global attainment for your research

- Article availability in different formats (Pdf, E-pub, Full Text)

- Endless customer service

- Reasonable Membership services

- Reprints availability upon request

- One step article tracking system 